\title{
Classification of a burnt area based on spectral images
}

\author{
Anna Szajewska, ${ }^{1, *}$ \\ ${ }^{1}$ The Main School of Fire Service, Faculty of Fire Safety Engineering, 54/54 Slowackiego St., 01-629 \\ Warsaw, Poland
}

\begin{abstract}
The use of remote sensing techniques allows obtaining information about processes that occur on the surface of the Earth. In the aspects of fire protection and forest protection, it is important to know a burnt area which was created as a result of a fire of the soil cover or a total fire. The knowledge of this area is necessary to assess losses. Remote sensing techniques allow obtaining images in various spectral ranges. Remote sensing satellites offer multi-band data. Mathematical operations that operate on values coming from different spectral ranges allow determining various remote sensing indicators. The manuscript presents the possibility of using the NDVI (Normalized Difference Vegetation Index) to classify the burnt area. The NDVI is relatively easy to obtain because it operates in the spectral ranges from 630 up to $915 \mathrm{~nm}$, and is obtainable with one detector only. Thus, it can be obtained without any major problems using unmanned aerial vehicles, regardless of time and cloudiness, as is the case when acquiring satellite images. The manuscript describes experimental research and presents the results.
\end{abstract}

\section{Introduction}

In recent years, the rapid development of satellite technology has resulted in intensive research in the field of remote sensing methods. Intensified research has resulted in the development of various indicators that are determined mathematically based on various spectral ranges that can be obtained from transducers placed in remote sensing satellites. The first satellites had a limited measuring range but it already covered several channels in visible light and in near and far infrared. The latest satellites allow transmitting multispectral data which in its data structure has even several dozen narrow spectral channels. However, it should be noted that satellite measurements are burdened with two major difficulties which are not likely to be excluded in the near future. The first problem concerns cloudiness which radically disturbs the whole measurement. The second limitation is the flight time of a satellite over a selected area. This time is strictly determined and pictures are taken at rare intervals, and their result is additionally dependent on the weather that is available for a narrow time window at the selected area. In other words, the logical sum of the time window and cloudiness is imposed on the failure of the measurement to be made on any given day. However, large-area multispectral images can be taken not only

\footnotetext{
*Corresponding author: aszajewska@sgsp.edu.pl
} 
using satellites. Drones can be used for this purpose or for testing - hydraulic booms which was done for the purpose of these measurements. The article presents an experimental classification of a burnt area based on the spatial distribution of the NDVI [1]. The digital image analysis was used to classify the burnt area. The digital analysis that allows determining the NDVI was made on the basis of images obtained using one universal transducer in visible light and near infrared from a small height. Under appropriate conditions, the described method is an alternative to previous methods of observation and manual measurements of the burnt area as a result of fires on the soil cover. The assumption of the experiment was to determine the area burnt based on recorded images with minimal equipment facilities and without the use of data from remote sensing satellites due to their time and weather limitations.

\subsection{NDVI biomass vegetative index}

The origin of use of the biomass vegetative index lies in the physical properties of living plants and results from various properties of transmission or reflection of electromagnetic radiation for various spectral ranges. The NDVI is the basic indicator of vegetative activity and is determined by means of equation 1 based on two values:

$$
N D V I=\frac{N I R-R E D}{N I R+R E D}
$$

where:

NIR - the amount of light reflected in the near infrared band;

RED - the amount of light reflected in the red band $[2,3]$.

The essence of the NDVI index is the fact that observed objects that are photosynthetically active absorb radiation with a wavelength in the range of $0.4-0.7 \mu \mathrm{m}$, whereas radiation in the range of $0.7-1.1 \mu \mathrm{m}$ is absorbed to a small extent as shown in Figure 1.

so EXPLOITING SPECTRAL RESPONSE CURVES

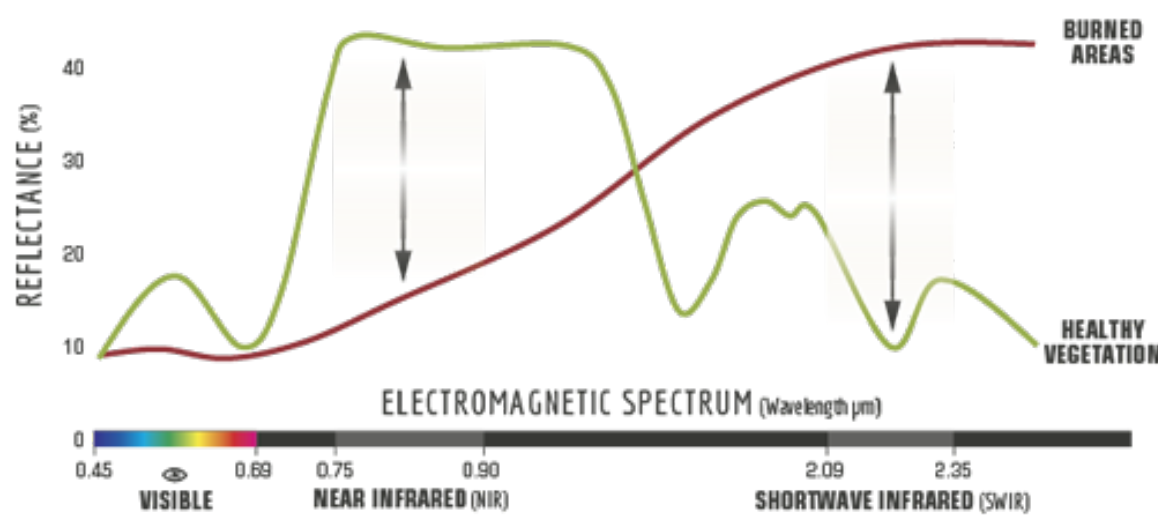

Fig.1. Reflection curves of vegetation and a burnt area [4].

Over $40 \%$ of NIR radiation is reflected from biomass. Thus, this index shows the contrast between the reflection in the near-infrared band and absorption in the red band [5]. There are also other metrics that relate relatively well to burnt places: MIRBI (Mid Infrared Burned Index) [6], BAIM (Burned Area Index adapted to MODIS) [7] and NBR (Normalized Burn Ratio) [8] whose equations are shown below. 


$$
\begin{aligned}
& B A I M=\frac{1}{\left(p c_{N I R}-\rho_{N I R}\right)^{2}+\left(p c_{S W I R}-\rho_{S W I R}\right)^{2}} \\
& M I R B I=10 L S W I R-9,8 S S W I R+2 \\
& N B R=\frac{N I R-S W I R}{N I R+S W I R}
\end{aligned}
$$

where:

NIR - the amount of light reflected in the near infrared band;

SWIR - the amount of light reflected in the near-infrared band;

SSWIR- Shorter Short Wave Infrared;

LSWIR- Longer Short Wave Infrared;

$\mathrm{pc}_{\mathrm{NIR}}-$ constant 0.05 ;

$\rho_{\text {SWIR }}-$ constant 0.2 .

These indicators were largely developed for use in MODIS (Moderate Resolution Imaging Spectroradiometer) which is a key instrument in the latest satellites, i.e. TERRA and AQUA. It is worth noting that the output from MODIS consists of 36 narrow bands whose widths do not correspond to older spectrophotometers used in LANDSAT, and in popular and relatively cheap bandpass filters. Two detectors are needed to determine BAIM, MIRBI and NBR, because the second range of the tested spectrum (SWIR) is far beyond the reach of universal detectors that can measure both RED and NIR ranges with the same photosensitive sensor. For this reason, to simplify the method, it was decided to use the NDVI which can be obtained with one detector. The degree of burnout can be determined with a smaller error by means of differential measurement where the index difference before burnout and after burnout is calculated, but in case of random events which are undoubtedly fires of the soil cover it would require a systematic inventory of all areas at risk of fire. After normalization of all spectrograms the NDVI takes values from the -1 to 1 range. Table 1 presents characteristic values in relation to the observed materials.

Table 1. NDVI value [7, 9].

\begin{tabular}{|l|l|}
\hline The value of the NDVI & \multicolumn{1}{c|}{ Material description } \\
\hline$<\mathbf{0}$ & Dead material, roads, buildings, dead plants, soil \\
\hline $\mathbf{0 . . . 0 . 3 3}$ & sick plant material \\
\hline$<\mathbf{0 . 3 5}$ & burnt area \\
\hline $\mathbf{0 . 3 4} \ldots \mathbf{0 . 6 6}$ & Healthy plant material \\
\hline$>\mathbf{0 . 6 6}$ & Very healthy, young vegetation \\
\hline
\end{tabular}

A big problem is the overlap of the NDVI which assumes similar values for both the burnt area as well as for dead vegetation and artefacts of human activity.

\section{Experiment}

The study included a universal monochrome camera adapted to the $400-1000 \mathrm{~nm}$ range. The camera was equipped with an automatic bandpass filter changer with an electronic controller made according to its own concept. Figure 2 shows the measurement system placed in the hydraulic lift basket. The camera made duplicated spectrograms in the two mentioned ranges. The time interval between individual spectra was determined by the rate of change of the filter and it did not exceed $1 \mathrm{~s}$. 


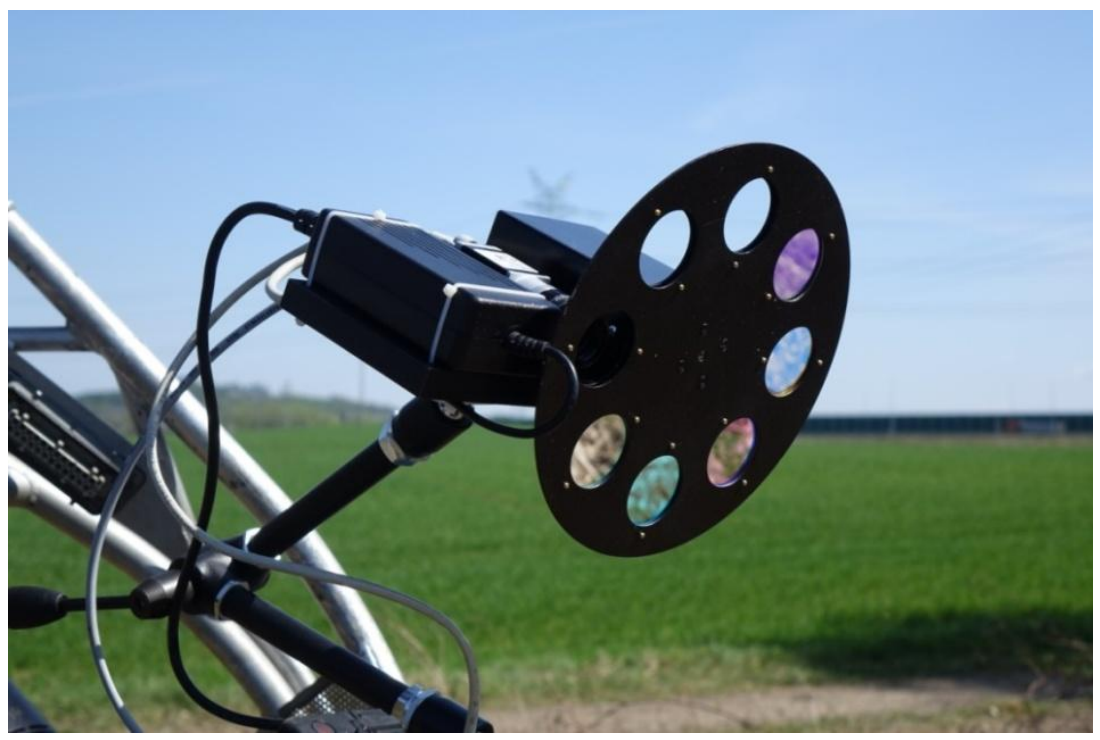

Fig. 2. Measuring stand placed in the hydraulic lift basket.

After the controlled burnout of the soil cover, spectral images were recorded at two heights in two wavelength ranges: $630 . .730$ and $815 . .915 \mathrm{~nm}$. Based on the pictures, the spatial distribution of the NDVI of the area was determined which was then subjected to a controlled burnout. The indexes were designated by computer using a proprietary program on a PC. Figure 3 shows the distribution of the NDVI and the picture of the tested area taken in visible light. The values of NDVI $<0.35$ are marked in red. In the area of the controlled burnout of the soil cover, there was a lot of dead and withered vegetation which partially took the index value $<0.35$. The burnt area was extinguished with water, which is also visible in Figures 3 and 4.

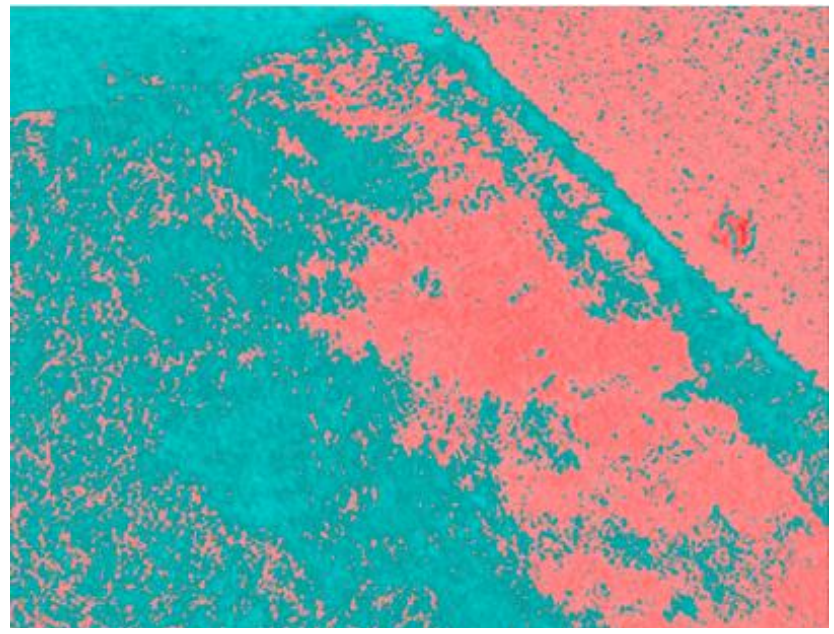

Fig. 3. Distribution of the NDVI subject to thresholding at a level of 0.35 . 


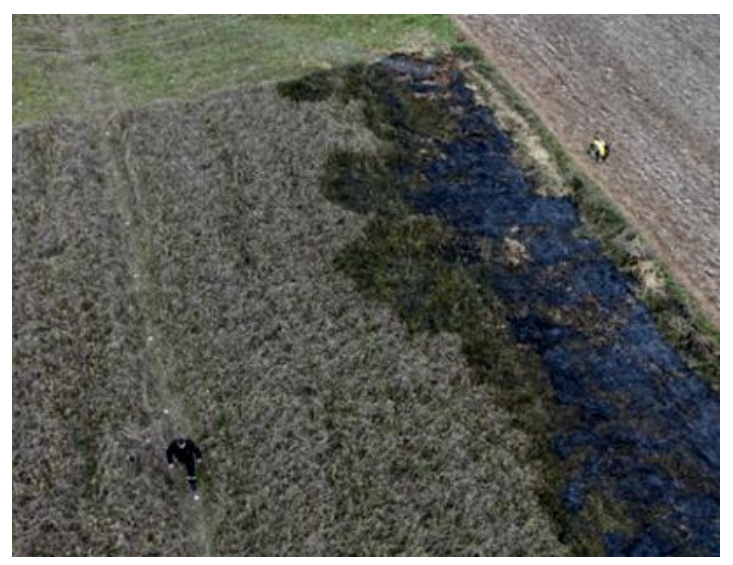

Fig. 4. Burnt area in visible light.

To the right of the burnt area there was a ploughed field with no vegetation. In this area the value of the index in $97 \%$ assumed the value of NDVI $<0.35$. The percentage value was estimated based on pixel counting with an NDVI value of $<0.35$ on a given area segment.

\section{Conclusions}

The computer analysis of NIR and RED spectrograms allows making a quick identification of the burnt area using the minimum of hardware. Using the NDVI for this purpose, the undoubted problem is the overlapping of the same values for the burnt area as for road buildings and exposed soil. Minor interpretation errors related to the presence of dead plants in areas of healthy vegetation can be quite easily reduced using subsequent morphological operations of erosion and growth for identified pixels whose values are below the accepted threshold. However, the exposed soil will be identified in the same way as the burnt area. The method can give satisfactory results assuming that in the neighbourhood of the burnt area there are areas with live vegetation only.

\section{References}

1. C. Tucker, Remote Sens. Environ. 8, 127 (1979)

2. J. Weier, D. Hemig, Measuring vegetation (NDVI\&EVI) (NASA, Earth Observatory, 2000)

3. Praca zbiorowa, Geomatyka w lasach państwowych Part I. (CILP, 2010)

4. http://gsp.humboldt.edu/olm_2015/Courses/GSP_216_Online/lesson5-1/NBR.html

5. J.W. Rouse, R.H. Haas jr., J.A. Schell, D.W. Prog. Rep. RSC 1978-1, Remote Sens. Center, Texas A\&M Univ., College Station, 93 (NTIS No. E73- 106393), (1973)

6. L. Schepers, B. Haest, S. Veraverbeke, T. Spanhove, J.V. Borre, R. Goossens, Remote Sens. 6, 1803 (2014)

7. P. Martin, I. Gómez1 \& E. Chuvieco, Proceedings of the 5th International Workshop on Remote Sensing and GIS Applications to Forest Fire Management: Fire Effects Assessment: 193-197 Universidad de Zaragoza, (2005)

8. S. Trigg, S. Flasse, Int. J. Remote Sens. 22, 2641 (2001)

9. A. Szajewska, Termowizja w ochronie przeciwpożarowej (SGSP, Warsaw, 2018) 